\title{
COLOSTOMY RELATED MORBIDITY AND MORTALITY IN NEONATES WITH ANORECTAL MALFORMATION
}

\author{
Dhirendra Shrivastava1, Swati Jain ${ }^{2}$, Kuldeep ${ }^{3}$, Abhishek Choubey ${ }^{4}$
}

${ }^{1}$ Assistant Professor Department of Paediatric Surgery, Gandhi Medical College, Bhopal.

2Medical Officer, Department of Paediatric Surgery, Gandhi Medical College, Bhopal.

${ }^{3}$ Resident Surgical Officer, Department of Paediatric Surgery, Gandhi Medical College, Bhopal.

${ }^{4}$ Resident Surgical Officer, Department of Paediatric Surgery, Gandhi Medical College, Bhopal.

\begin{tabular}{l}
\hline ABSTRACT \\
BACKGROUND \\
Colostomy is a life-saving procedure in newborns with high/intermediate Anorectal Malformations (ARM). However, the \\
procedure maybe attended by complications particularly in resource limited settings.
\end{tabular}

\section{AIM}

This study analyses the morbidity and mortality related to colostomy formation in neonates with ARM at tertiary care centre.

\section{SETTINGS AND DESIGN}

Department of Paediatric Surgery, Gandhi Medical College, Bhopal. A retrospective evaluation.

\section{METHOD}

Neonates who underwent colostomy for high or intermediate ARM in two year duration were included in the study. Patients in whom colostomy was done for reason other than ARM were excluded from the study.

\section{RESULT}

124 patients with ARM reported to our institute in two years (January 2013-January 2015) duration. There were 72 male and 52 female neonates with ARM of age range between 1-4 days and weighing 1.5-2.6 kg. 60 patients had low anomaly and were treated with anoplasty while 64 had high/intermediate anomaly and were managed with colostomy. 10 patients underwent transverse loop colostomy while 54 had sigmoid loop colostomy. 55 patients developed complications related to colostomy, which included skin excoriation $(62 \%)$, stoma prolapse $(23.4 \%)$, bleeding $(12.5 \%)$, obstruction $(4.68 \%)$, wound infection $(9.37 \%)$, and retraction (6.25\%). Mortality was in $12.5 \%$ cases.

\section{CONCLUSIONS}

There is substantial morbidity associated with colostomy formation in neonates with ARM at our limited resource centre. Refinements in surgical technique along with comprehensive postoperative care may facilitate to reduce these complications following colostomy in ARM.

\section{KEYWORDS}

Anorectal Malformation, Colostomy, Neonates.

HOW TO CITE THIS ARTICLE: Shrivastava D, Jain S, Kuldeep, et al. Colostomy related morbidity and mortality in neonates with anorectal malformation. J. Evolution Med. Dent. Sci. 2016;5(68):4882-4884, DOI: 10.14260/jemds/2016/1110

\section{INTRODUCTION}

The worldwide incidence of Anorectal Malformations (ARM) is 1:4000-5000 live births and could vary in Indian patients. $(1,2)$ Colostomy is a part of staged reconstruction of ARM to relieve the obstruction and also to prevent surgical site contamination at the time of definitive repair of ARM.(3) There are different surgical options for colostomy depending on the site of obstruction such as transverse loop/divided or sigmoid loop/divided loop colostomy. These approaches have advantages and disadvantages. In loop colostomy, risk of urinary tract infections is common due to faecal contamination.

Financial or Other, Competing Interest: None.

Submission 07-07-2016, Peer Review 11-08-2016,

Acceptance 17-08-2016, Published 24-08-2016.

Corresponding Author:

Dr. Dhirendra Shrivastava,

Assistant Professor,

Department of Paediatric Surgery,

Gandhi Medical College,

Bhopal-462001,

Madhya Pradesh.

E-mail: shridhirendra@gmail.com

DOI: $10.14260 / \mathrm{jemds} / 2016 / 1110$
In patients with ARM, the decision to perform colostomy is based on the type/site of anomaly (high/intermediate), condition of the patient and surgeon's preference/expertise. Despite better understanding and innovations in surgical technique/management of ARM, there are various complications of colostomy, which maybe either procedure/approach related or deficiencies in postoperative care. $(3,4,5)$

The aim of this study was to evaluate the common complications related to colostomy done as staged procedure in neonates with ARM.

\section{METHOD}

This study was conducted as retrospective analysis of complications related to colostomy performed for ARM in neonates attending Department of Paediatric Surgery between 2013 and 2015. All patients underwent colostomy under general anaesthesia. The patients who underwent colostomy for reason other than ARM were excluded from the study.

The parameters which were analysed from clinical records of the operated patients at colostomy include age, weight, type of ARM, colostomy stoma site, type of colostomy, and complications related to colostomy formation. 
Anorectal anomalies were classified according to Kiely and Pena(6) as perineal fistula, recto-urethral fistula, rectovesical fistula, imperforate anus without fistula, and rectal atresia in males and perineal fistula, vestibular fistula, persistent cloaca, imperforate anus without fistula, and rectal atresia in female neonates. High/intermediate anomalies include recto-urethral fistula, rectovesical fistula, and rectal atresia/cloaca. Colostomy was not done in neonates with low anomaly, which includes perineal fistula and vestibular fistula.

\section{RESULTS}

The total number of neonates with ARM reported at the department during this period was 124 . The age was ranged between one day to 4 days; weight was between $1.5 \mathrm{~kg}$ to 2.4 kg. 72 were males and 52 were females. 60 neonates had low anomaly and were treated with anoplasty.

64 neonates had high/intermediate anomaly and were managed with colostomy. Out of 64 patients, 18 patients underwent transverse loop colostomy while 46 had sigmoid loop colostomy. All patients with anorectal malformation were worked up with invertogram and abdominal ultrasound. Echocardiography could not be done in all the cases.

55 patients developed complications following colostomy procedure. The complications of colostomy formation observed were skin excoriation (62\%), stoma prolapse (23.4\%), bleeding (haemorrhage) (12.5\%), obstruction (stenosis) (4.68\%), wound infection (9.37\%), and retraction (6.25\%). Followup was up to one year or till closure of colostomy following definitive procedure. Mortality was observed in $12.5 \%$ cases. The most important cause of mortality was development of neonatal infection and sepsis especially in low birth weight neonates.

\begin{tabular}{|c|c|c|}
\hline Complication & Number & Percentage \\
\hline Skin excoriation & 48 & $62.5 \%$ \\
\hline Prolapse & 15 & 23.43 \\
\hline Bleeding & 8 & 12.5 \\
\hline Obstruction & 3 & 4.68 \\
\hline Wound infection & 6 & 9.37 \\
\hline Retraction & 4 & 6.25 \\
\hline
\end{tabular}

Total colostomy 64 ( n 64)

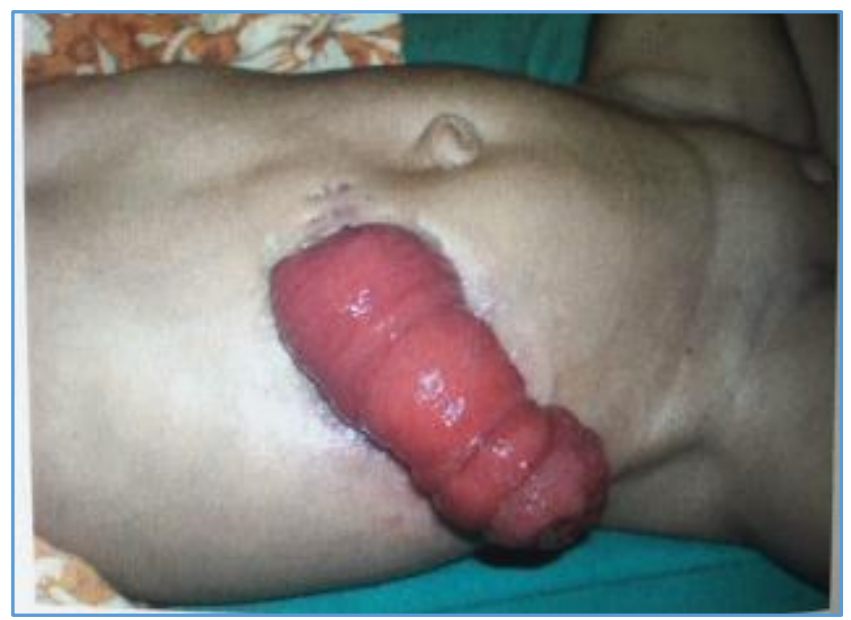

Fig.1: Colostomy Prolapse - Complication of Colostomy for ARM

\section{DISCUSSION}

The management of a newborn with an anorectal anomaly is crucial. Presentation is at times delayed especially in developing countries and such patients are at risk of associated abdominal distension, dehydration, and sepsis. Initial resuscitation with intravenous fluid and broadspectrum antibiotics holds the key for the final outcome in such cases. As the referral to this tertiary centre is usual after one to two days and more by that time patient develops distension and after assessment of associated anomalies.(7) The child can be taken for a protective colostomy followed by delayed repair later or a single staged definitive procedure can be performed in selected cases.(8)

Colostomy is done as staged procedure for management of ARM, which relieves the obstruction and also allows the radiological evaluation (distal colostogram), which facilitates the visualisation of the level of the defect and presence of associated fistulas.(9) The diversion of faecal content by stoma formation is valuable for wound healing at the time of definitive surgery and also improves the continence in these patients with ARM because covering colostomy protects the operative site from faecal contamination and helps healing.

The colostomy formation done for ARM is associated with a number of complications(10) and had mortality associated with it. This procedure done in neonates should not be considered as a procedure of little complexity. The worldwide incidence of colostomy-related complications ranges from 28$74 \%$. Variety of complications has been reported in the literature. $(11,12,13)$ Skin excoriation is the most common complication occurring following colostomy and is managed by local application of rash free cream. Management of complications not included in this study needs separate work up and study design. Other common complications include stoma prolapse, bleeding, intestinal obstruction, wound infection, and retraction. In our study, incidence of complications is $\sim 65 \%$, which is quiet high compared to other studies.(11,14) The reason for difference in incidence maybe due to differences in type of colostomy/technique performed and also specialised neonatal intensive care available at these centres they have special stoma care units and trained personnel for this.

At our resource limited institution, the majority of colostomy formations were of the loop type using the sigmoid colon. Various investigators $(3,15,16)$ have recommended a divided colostomy at the junction of the descending and the sigmoid colon because of many advantages such as manageable small stoma with minimal chances of prolapse; distal loop faecal impaction is eliminated. The subsequent pull-through procedure is also free of tension in this technique as sufficient length of colon distal to the stoma is available. Risk of urinary tract infections is also reduced in divided colostomy as mentioned in literature.

This study highlights the potential morbidity associated with colostomy formation in neonates with anorectal malformations. This also indicates high incidence of complications in comparison to the advanced centres at the resource limited centre teaching hospital managing these patients. The reason for high incidence deserves to be taken in consideration to evolve a strategy and to implement comprehensive care, the training, and teaching of caregivers and parents, which is needed to improve the survival and to reduce the avoidable morbidity in these patients. Outcome may be significantly improved with multimodal interventions in the perioperative care of patients undergoing this 
procedure. ${ }^{17}$ Also, it is not only the surgical technique, but also the postoperative care and ongoing education regarding stoma care that can make positive impact on long-term quality of life of these patients.

\section{REFERENCES}

1. Stephens FD, Smith ED. Classification, identification, and assessment of treatment of anorectal anomalies. Paediatr Surg Int 1986;1(4):200-5.

2. Stephen FD, Smith ED. Anatomy and function of the normal rectum and anus; individual deformities in the male; operative management of anal deformities. Anorectal malformations in children. Chicago, IL: Year Book Medical Publishers 1971:212-73.

3. Wilkins S, Pena A. The role of colostomy in the management of anorectal malformations. Paediatr Surg Int 1988;3(2):105-9.

4. Mollitt DL, Malangoni MA, Ballantine TV, et al. Colostomy complications in children: an analysis of 146 cases. Arch Surg 1980;115(4):455-8.

5. Bishop H. Colostomy in the newborn. Am J Surg 1961;101(5):642-8.

6. Kiely EM, Pena A. Anorectal malformations. In: O'Neill JA, Rowe MI, Grosfeld JL, et al, eds. Paediatric Surgery. St. Louis, MO: Mosby 1998:1425-48.

7. Alam MS, Chowdhury MK, Islam MK. Urogenital anomalies associated with anorectal malformations in children. Mymensingh Med J 2006;15(2):128-30.
8. Chowdhary SK, Chalapathi G, Narasimhan KL, et al. An audit of neonatal colostomy for high anorectal malformation: the developing world perspective. Paediatr Surg Int 2004;20(2):111-3.

9. Patwardhan N, Kiely EM, Drake DP, et al. Colostomy for anorectal anomalies: high incidence of complications. J Paediatr Surg 2001;36(5):795-8.

10. Weber TR, Tracy TF, Silen ML, et al. Enterostomy and its closure in newborns. Arch Surg 1995;130(5):534-7.

11. Nour S, Beck J, Stringer MD. Colostomy complications in infants and children. Ann R Coll Surg Engl 1996;78(6):52630.

12. Sheikh MA, Akhtar J, Ahmed S. Complications/problems of colostomy in infants and children. J Coll Physicians Surg Pak 2006;16(8):509-13.

13. Pena A, Migotto-Krieger M, Levitt MA. Colostomy in anorectal malformations: a procedure with serious, but preventable complications. J Paediatr Surg 2006;41(4):748-56, discussion 748-56.

14. Miller AJ, Lakhoo K, Rode H, et al. Bowel stomas in infants and children. A 5-year audit of 203 patients. S Afr J Surg 1993;31(3):110-3.

15. Shaul DB, Harrison EA. Classification of anorectal malformations-initial approach, diagnostic tests, and colostomy. Semin Paediatr Surg 1997;6(4):187-95.

16. Chandramouli B, Srinivasan K, Jagdish S, et al. Morbidity and mortality of colostomy and its closure in children. J Paediatr Surg 2004;39(4):596-9.

17. Nanavati AJ, Prabhakar S. Fast-tracking colostomy closures. Indian J Surg 2015;77(Suppl 3):1148-53. 